\title{
HAVERÁ DIFERENÇAS INDIVIDUAIS NA CAPACIDADE PARA DETECTAR A MENTIRA E A HONESTIDADE NOS OUTROS?
}

\author{
Andreia Rodrigues ${ }^{1}$ \\ Patrícia Arriaga ${ }^{2}$
}

Resumo: Este artigo investigou se diferenças individuais, como o género e a inteligência emocional, contribuem para a detecção da mentira e da honestidade. Adicionalmente, foram analisados os indícios usados nos julgamentos de mentira. Noventa estudantes universitários de ambos os sexos foram expostos a oito gravações em vídeo que exibiam pessoas adultas (quatro homens e quatro mulheres) a responder às mesmas questões numa entrevista (metade mentiu; a outra metade foi honesta). No geral, a percentagem de respostas correctas para a deteç̧ão da mentira foi aproximadamente o que seria de esperar em respostas ao acaso; para a detecção da honestidade a precisão foi inferior a valores ao acaso. Os participantes também responderam com maior frequência que os alvos foram "desonestos", sugerindo um enviesamento nos seus julgamentos. Os acertos não se mostraram associados à maioria das dimensões de inteligência emocional. Em relação a diferenças de género, os participantes do sexo masculino foram significativamente mais precisos na detecção da mentira, enquanto as mulheres foram mais precisas na detecção da honestidade, independentemente do género do alvo. Várias possíveis explicações emergiram e foram discutidas com base na pesquisa e teoria nesta área.

Palavras-chave: detecção da mentira e honestidade, diferenças individuais, género, inteligência emocional

\footnotetext{
${ }^{1}$ BioEpi, Clinical \& Translational Research Center

2 Instituto Universitário de Lisboa (ISCTE-IUL), Centro de Investigação e Intervenção Social (Cis-IUL), Lisboa, Portugal

A correspondência relativa a este artigo poderá ser enviada para: Patrícia Arriaga (patricia.arriaga@iscte.pt), Instituto Universitário de Lisboa (ISCTE-IUL), Centro de Investigação e Intervenção Social (Cis-IUL), Avenida das Forças Armadas, 1649-026 Lisboa.

Os autores contribuíram de igual forma para o presente artigo. Os resultados preliminares deste estudo foram publicados nas Actas do VII Simpósio Nacional de Investigação em Psicologia, da Associação Portuguesa de Psicologia. Universidade do Minho, Braga, Fevereiro de 2010.
}

PSICOLOGIA, Vol. XXIV (2), 2010, Edições Colibri, Lisboa, pp. 43-60 
Are there individual differences in the ability to detect lie and honesty in others? (Abstract): This article examined whether individual differences, such as gender and emotional intelligence, contribute to detecting lying and honesty. Additionally, the cues used in judgments about lying were analysed. Ninety male and female university students were exposed to eight videotapes showing adult persons (four men and four women) answering the same questions in an interview (half were telling the truth; the other half were lying). Overall, the percentage of accurate lie detection was nearly what would be expected by chance; accurate honesty detection was below chance. Participants also responded more often that targets were "dishonest", suggesting that a bias occurred in their judgments. Accuracy was unrelated to most emotional intelligence dimensions. Regarding gender differences, male participants were significantly more accurate in detecting lying, whereas women were more accurate in detecting honesty, regardless of the gender of the target. Several possible explanations were raised and discussed based on research and theory in this area.

Keywords: detecting lying and honesty, individual differences, gender, emotional intelligence

Para o senso comum, mentir é considerado um acto imoral e que facilmente é detectado (Masip, 2005). A mentira faz parte do nosso desenvolvimento social, sendo um aspecto marcante nas nossas relações sociais (Gervais, Tremblay, \& Héroux, 1998). Aprendemos a diferenciar os contextos onde a mentira pode ser usada e o tipo de mentira que é mais adequado. Mentir é, assim, um comportamento complexo, que pode estar associado a características individuais bem como ao contexto social. Embora várias definições de "mentira" tenham sido propostas, no presente artigo este conceito é definido como "a mensagem que uma pessoa transmite a outra, na qual está deliberadamente a enganá-la” (Ennis, Vrij, \& Chance, 2008, p. 105).

A maioria dos estudos sobre detecção da mentira tem avaliado a precisão com que as pessoas conseguem detectar a mentira e os indícios utilizados. O procedimento mais comum é a apresentação de entrevistas em vídeo, onde se pede uma avaliação ao observador sobre a veracidade ou a mentira das afirmações de outras pessoas. Por vezes, também se questiona os indícios usados pelo observador e a sua confiança no julgamento efectuado.

A investigação tem revelado que a probabilidade de detectar a mentira é pouco superior a 50\%, indicativa de acertos ligeiramente acima do acaso (e.g., Crossman, \& Lewis, 2006; Ekman, Franck, \& O'Sullivan, 1999; Vrij, 2004). Assim, ao contrário da ideia de senso comum de que somos facilmente capazes de detectar a mentira nos outros, a investigação tem mostrado a dificuldade em o fazer. 
De um modo geral, os julgamentos sobre a mentira baseiam-se em indícios não-verbais e verbais, embora haja uma maior tendência para inferir a mentira a partir de indícios não verbais (Vrij \& Taylor, 2003). Os comportamentos que são percebidos como mais denunciadores da mentira são: desviar o olhar, estar nervoso, corar, exibir muitos movimentos corporais (sobretudo com braços e mãos), hesitar, fazer pausas no discurso, ter um discurso inconsistente e incoerente (The Global Deception Team, 2006). A investigação tem também mostrado que as crenças sobre o modo como as pessoas reagem quando mentem são partilhadas pelas pessoas em geral e por profissionais que trabalham nessa área, embora sejam na sua maioria incorrectas (Mann, Vrij, \& Bull, 2004; Vrij, 2004; Vrij \& Taylor, 2003). Estes resultados podem estar relacionados com dificuldades dos observadores em identificar a mentira, com a capacidade dos observados em ocultar a mentira, ou com ambos os factores (Edelstein, Goodman, Ekman \& Luten, 2006). Um dos argumentos a favor da manifesta dificuldade das pessoas em detectar a mentira prende-se com o facto de se basearem em indícios opostos à presença de mentira. Efectivamente, ao contrário das ideias de senso comum, a investigação tem mostrado que, quando mentem, as pessoas procuram controlar as suas emoções (i.e., suprimir o nervosismo), o que geralmente se traduz na falta de espontaneidade, pouco envolvimento, reduzida manifestação de movimentos corporais, e pouca frequência de desvio do olhar e do pestanejar (Vrij, 2004).

Parece também existir ainda uma maior tendência para julgar os outros como honestos do que mentirosos (Levine, Park \& McCornack, 1999). Na maioria das vezes, as pessoas tendem a formar uma boa impressão sobre a honestidade dos outros (Stapel, Koomen, \& van der Pligt, 1996). A formação de julgamentos sociais positivos baseados na honestidade e na credibilidade do outro pode ter vantagens sociais importantes, justificando por isso o facto de dirigirmos mais a atenção para indícios que sugerem que a pessoa está a ser honesta. Sendo assim, é mais fácil julgar a mentira como verdade do que julgar a verdade como mentira. Há, no entanto, excepções. Por exemplo, as pesquisas desenvolvidas por Ekman e colaboradores (Ekman \& O'Sullivan, 1991; Ekman, O’Sullivan, \& Frank, 1999) evidenciaram resultados opostos em amostras de agentes policiais; no geral, estes indivíduos foram mais precisos na identificação da mentira do que da honestidade. Segundo os autores, o facto de estes grupos de profissionais lidarem com criminosos, pode explicar a maior desconfiança nos alvos e um maior enviesamento na detecção da mentira. Relativamente à percepção dos adultos em detectar a mentira em crianças, Crossman e Lewis (2006) também verificaram que, quando na folha de resposta lhes era retirada a hipótese de resposta "não sei", os adultos tendiam a percepcionar as crianças como sendo mais mentirosas do que honestas. Edelstein e co-autores (2006) compara- 
ram a detecção da mentira em adultos e crianças-alvo, tendo verificado que a mentira foi detectada com mais precisão nas crianças do que nos adultos, e que a verdade foi melhor detectada nos adultos. Verificaram também uma forte relação entre a capacidade para detectar a mentira nas crianças e a detecção de mentira nos adultos, o que sugere a possível existência de características individuais nesta capacidade.

Entre os vários factores que podem contribuir para a detecção da mentira, a motivação do autor para mentir, a preparação e a experiência do observador, têm sido referidos como os mais relevantes (Bond \& De Paulo, 2006). Esta maior aptidão foi igualmente verificada em indivíduos que, por razões profissionais, lidavam com a detecção da mentira (agentes de serviços secretos, juízes, psicólogos). No estudo de Ekman e O'Sullivan (1991), entre os vários grupos de profissionais estudados, o grupo de agentes de serviços secretos foi o que obteve uma percentagem de acertos superior. É importante destacar que, embora os profissionais consigam detectar com maior precisão a mentira do que a população em geral, a percentagem de acertos também tem sido ligeiramente acima dos $50 \%$, embora seja superior quando se baseia simultaneamente em indícios verbais e não verbais (Vrij, 2004).

A pesquisa sobre as variáveis individuais do observador associadas a maior capacidade de detectar a mentira não tem evidenciado resultados consistentes. Em termos de diferenças de género, alguns estudos têm mostrado que as mulheres tendem a ser mais precisas do que os homens em descodificar comunicação não verbal (Hall, 1984). Porém, ao nível da detecção da mentira, a investigação sugere que não há diferenças de género, embora possam existir factores moderadores que evidenciem diferenças de género. Por exemplo, a meta-análise conduzida por Aamodt e Custer (2006) mostra que, no geral, não há diferenças de género na detecção da mentira. Porém, ao verificarem que a percentagem da variabilidade devido a erro da amostragem era inferior a $75 \%$, foram investigar potenciais moderadores. Verificaram que os homens responsáveis pela aplicação da lei (e.g., corporações policiais) eram os mais eficientes a detectar a mentira, enquanto no grupo de não profissionais na área, as mulheres eram ligeiramente mais eficientes do que os homens. No entanto, os autores alertam para o facto de estas diferenças serem marginais e estatisticamente não significativas. Em meta-análises conduzidas por outros autores não foram identificadas diferenças de género (Bond \& DePaulo, 2006, 2008). Parece-nos, no entanto, relevante ter em consideração, não apenas a capacidade de detectar a mentira, mas outros factores que poderão evidenciar formas distintas na avaliação da honestidade e da mentira. Por exemplo, a investigação tem sido inconclusiva a propósito dos indícios que os homens e as mulheres sinalizam durante a avaliação da mentira. A este propósito, Hurd e Noller (1988) verificaram que as mulheres recorrem a um maior número de indícios do que os homens e demoram mais 
tempo a tomar uma decisão, em particular quando se trata de avaliar a mentira e a honestidade dos homens. Verificaram ainda que as mulheres tendem a prestar mais atenção a indícios explícitos do que encobertos, quando avaliam alvos do sexo oposto. Por contraste, os homens expressam maior confiança nos seus julgamentos em geral (embora maior desconfiança quando avaliam a honestidade do que a mentira) e demoram menos tempo a formar uma opinião.

Numa outra perspectiva, a investigação também não tem mostrado diferenças de género na frequência com que os homens e as mulheres mentem, apesar de se diferenciarem na forma e tipo de mentira, dependendo da natureza da relação (e.g., DePaulo, Epstein, \& Wyer, 1993; DePaulo, Kirkendol, Kashy, Wyer, \& Epstein, 1996). Apesar de as pessoas terem tendência para mentir em benefício próprio, DePaulo e co-autores $(1993,1996)$ referem diferenças de género nas motivações e tipo de mentira: por comparação com os homens, as mulheres tendem a mentir com motivações mais orientadas para os outros e a mentir menos para benefício próprio. Mas o mais interessante nos resultados obtidos por DePaulo e co-autores (1996) foi o facto de este tipo de mentira - orientada para o outro - ser mais predominante nas interacções entre mulheres do que na interacção de mulheres com elementos do sexo oposto. A investigação em outros domínios mostra diferenças de género nas interacções sociais. Por exemplo, em interacções com elementos do mesmo sexo, as mulheres tendem a exibir menos comportamentos de valorização pessoal do que quando interagem com um homem; este tipo de comportamento tende a ocorrer com menor frequência quando comparado com as interacções dos homens com o mesmo sexo ou com o sexo oposto (DePaulo et al., 1996). Efectivamente, os homens e as mulheres manifestam, desde a infância, experiências de socialização distintas, havendo uma maior tendência para o desenvolvimento de laços de maior proximidade entre elementos do mesmo sexo (Maltz \& Borker, 1982). A maior proximidade entre elementos do mesmo sexo poderá contribuir para uma maior precisão na compreensão do outro e na partilha de estilos de comunicação.

As diferenças atrás mencionadas levam-nos a considerar a importância de analisar, não apenas diferenças de género na capacidade de detectar a mentira, mas também de explorar a interacção entre o sexo do observador e o sexo do alvo em julgamentos de mentira e de honestidade.

Vários autores sugerem ainda que a capacidade de detectar a mentira poderá estar associada a certas aptidões individuais. A investigação nesta área é reduzida e por esta razão torna-se difícil concluir sobre o papel de traços ou de outras características individuais na detecção da mentira. Por exemplo, Aamodt e Custer (2006) identificaram apenas três estudos que mediram o Neuroticismo, cinco estudos que avaliaram a Extroversão e quatro estudos a Auto-monitorização. Apesar da impossibilidade de extrair uma conclusão com base neste limitado número de estudos, os autores destacam 
como potencial preditora da detecção da mentira, a auto-monitorização, i.e., a tendência de um indivíduo para monitorizar, no ambiente e nos outros, indícios que lhe permitam regular e controlar o seu comportamento, de modo a adequar-se a situações sociais e relações interpessoais. Destaque-se ainda que a investigação de Schutte e colaboradores (2001) mostrou uma relação positiva entre a auto-monitorização e a inteligência emocional (IE), sugerindo que características como a capacidade de compreensão das emoções dos outros e de empatia (centrais ao conceito de IE) possam facilitar a auto-monitorização, no sentido de uma melhor adaptação às circunstâncias sociais.

Nesta perspectiva, considerámos a possibilidade de a IE poder estar associada à capacidade de detectar com maior precisão a mentira (cf. Edelstein et al., 2006). Segundo Ekman e O'Sullivan (1991), os indivíduos com mais acertos na detecção da mentira possuiriam uma maior capacidade para detectar e descodificar a informação que é transmitida pelo outro. É neste sentido que introduzimos nesta investigação a eventual relevância da IE na detecção da mentira e da honestidade nos outros.

O conceito de IE surgiu nos anos 90 através de Salovey e Mayer (cf. Rego \& Fernandes, 2005) e tem sido definido como a capacidade de percepcionar e expressar as emoções, perceber, utilizar e gerir as emoções próprias e dos outros. Este conceito tem sido muito debatido na comunidade científica, existindo ainda alguns problemas ao nível da sua definição e do seu enquadramento enquanto factor de "inteligência" ou como dimensão de "personalidade". De um modo geral, a IE engloba quatro capacidades básicas: a regulação de emoções; a compreensão e análise de emoções; o acesso a emoções que auxiliem processos cognitivos e a aptidão para percepcionar, avaliar e expressar emoções (Rego \& Fernandes, 2005). Para avaliar este conceito, a maioria das medidas desenvolvidas tem sido de auto-avaliação ou de desempenho (Bueno \& Primi, 2003). Nas medidas de desempenho, a avaliação é externa e a sua administração tende a ser complexa. Nas avaliações por auto-relato tende a ocorrer maior enviesamento nas respostas, visto a avaliação ser interna, muito influenciada pela desejabilidade social e, por estas razões, poder não corresponder à realidade (Zeidner, Roberts \& Matthews, 2008).

A presente investigação surgiu com o propósito de tentar preencher uma lacuna na investigação relativa ao estudo da capacidade de detectar a mentira e da honestidade e sua relação com factores individuais, entre os quais destacámos para análise o género (do observador e do alvo) e a IE. Serão ainda estudados os indícios em que os participantes se baseiam durante este tipo de julgamentos.

Atendendo aos resultados de outras investigações (e.g., Crossman \& Lewis, 2006; Ekman et al., 1999), é esperado que ocorram dificuldades na deteç̧ão da mentira, o que corresponderá a uma média de acertos pouco superior a $50 \%$. 
Pelo facto de se efectuar a avaliação junto de alvos adultos, é esperado que os participantes detectem melhor a honestidade do que a mentira (cf. Levine et al., 1999), pelo que se espera um maior número de acertos quando o alvo é honesto do que quando é desonesto.

Em relação às variáveis individuais (género e IE), as análises serão exploratórias, na medida em que os resultados da literatura não são conclusivos. Porém, em termos teóricos, é possível avançar com algumas hipóteses.

De um modo geral, a pesquisa tem mostrado que a precisão deste tipo de julgamentos é semelhante para ambos os sexos. No entanto, é possível que existam diferenças em função do sexo do observador, do tipo de julgamento efectuado e dos indícios usados na formação dos julgamentos. As diferenças de género no modo de estabelecimento das relações interpessoais e estilos de comunicação, levam-nos a colocar a possibilidade de as díades do mesmo sexo manifestarem maior capacidade para detectar com precisão indícios de mentira e de honestidade nos alvos.

A nível de traços ou de outras características disposicionais, a pesquisa não tem encontrado evidências da sua associação à capacidade de efectuar julgamentos precisos de mentira e de honestidade (e.g., Bond \& DePaulo, 2006, 2008). No entanto, a nível teórico será de esperar que certas dimensões interpessoais de IE, como a compreensão das emoções nos outros e a empatia, possam estar associadas à capacidade de detectar com maior precisão indícios de mentira e de honestidade nos outros (e.g., Edelstein et al., 2006).

\section{Método}

\section{Participantes}

Participaram 90 estudantes universitários, 61 do sexo feminino $(67,8 \%)$ e 29 do sexo masculino (32,2\%). Os participantes tinham entre $18 \mathrm{e}$ 41 anos $(M=23,70 ; D P=4,58)$. As suas habilitações literárias variavam entre 12 e 16 anos de escolaridade completos $(M=13,70 ; D P=1,6)$.

\section{Medidas}

Honestidade e Mentira do alvo. Para a manipulação intra-sujeitos da honestidade (vs. mentira) do alvo, filmaram-se oito entrevistas a estudantes de Psicologia entre os 22 e 30 anos de idade. Estes indivíduos aceitaram colaborar na investigação e assinaram um consentimento informado para autorizar o uso do vídeo na experiência. Foram constituídos dois grupos: um grupo honesto e outro grupo que mentiu em todas as perguntas da entrevista. Cada grupo ficou composto por quatro elementos: dois rapazes e duas raparigas. Foi-lhes apenas dito que iriam participar num jogo, seguido de uma 
entrevista e filmagem. Aos estudantes do grupo que mentiu foi-lhes pedido que mentissem da melhor forma possível a todas as perguntas, como se estivessem a representar. A sessão de "jogo" foi adaptada do estudo de Edelstein e co-autores (2006), na qual uma assistente toca uma vez no nariz, na barriga, na orelha e no pescoço dos indivíduos; o grupo que mentiu não assistiu a essa sessão. Em seguida, todos os indivíduos foram submetidos a uma entrevista filmada em close-up, sem dissimulação da câmara de vídeo. Nessas entrevistas foram colocadas nove questões, baseadas na lista de perguntas usadas por Edelstein e co-autores (2006). A entrevista era assim composta pelas seguintes questões: (1) "Quantos anos tem?"; (2) "A assistente tocou-lhe?"; (3) "Ela tocou-lhe no nariz?"; (4) "Quantas vezes é que ela tocou no seu nariz?"; (5) "A assistente tocou-lhe na barriga?"; (6) "Quantas vezes é que ela lhe tocou?"; (7) "A assistente tocou-lhe na orelha?"; (8) "A assistente tocou-lhe no pescoço?"; (9) "Está a ser sincero?". As questões eram de resposta fechada. Para que o entrevistador não influenciasse as respostas dos indivíduos, as questões foram previamente gravadas e colocadas durante a entrevista mediante o recurso a um gravador. Cada entrevista teve a duração aproximada de um minuto. No fim da entrevista, foi dada uma informação (debriefing) sobre os principais objectivos da investigação e agradeceu-se a colaboração dos voluntários. As entrevistas foram editadas para um $D V D$, onde cada indivíduo-alvo foi identificado por um número, no menu principal.

Deteç̧ão da mentira e da honestidade. A capacidade de detectar a mentira e a honestidade dos alvos foi operacionalizada através do número de acertos dos participantes. Para este efeito, foi desenvolvido um questionário de resposta fechada, solicitando-se a avaliação da mentira ou da honestidade de cada alvo, com duas opções de resposta: honesto ou desonesto. Se o participante avaliasse o alvo como desonesto, era-lhe pedido que assinalasse os tipos de comportamentos que lhe permitiram afirmar que o alvo teria mentido. Os tipos de comportamentos que o participante podia assinalar foram baseados nos indícios do estudo desenvolvido pelos autores do grupo de investigação "The Global Deception Team" (2006), i.e., desvio do olhar, nervosismo, hesitar, corar, movimentos corporais, a expressão facial, as pausas no discurso, a inconsistência e a incoerência do discurso. Neste inquérito foi ainda pedido que o participante assinalasse se conhecia os indivíduos sob observação e avaliação.

Inteligência Emocional. Para avaliar a IE foi usada a escala de auto-relato de Inteligência Emocional da autoria de Rego e Fernandes (2005). Esta escala é composta por 21 itens com formato de resposta de sete pontos, que variam entre 1 ("A afirmação não se aplica rigorosamente nada a mim") e 7 ("A afirmação aplica-se completamente a mim"). A escala avalia as seguintes seis dimensões: (1) Sensibilidade Emocional, que engloba a percepção das emoções do próprio e dos outros e o auto-controlo quando sub- 
metido a críticas (e.g., "Tenho dificuldade em conversar com pessoas que não partilham pontos de vista idênticos aos meus"); (2) Empatia, correspondente à capacidade de sintonia com os outros (e.g., "Quando algum amigo meu ganha um prémio, sinto-me feliz por ele"); (3) Compreensão das próprias emoções, referente à percepção, avaliação e expressão das emoções (e.g. "Sei bem o que sinto"); (4) Auto-encorajamento, respeitante ao uso das emoções (e.g., "Normalmente encorajo-me a mim próprio para dar o meu melhor"); (5) Compreensão das emoções dos outros (e.g., "Consigo compreender as emoções e sentimentos dos meus amigos vendo os seus comportamentos"); e (6) Auto-controlo emocional, abrangendo o controlo das emoções em situações de carga emocional (e.g., "Reajo com calma quando estou sob tensão"). O estudo de Rego e Fernandes (2005) mostrou que a IE apresenta boas qualidades psicométricas no geral, nomeadamente em termos de fidelidade, com valores de consistência interna adequados para todas as dimensões (i.e., alfa de Cronbach $>0,70$ ).

\section{Procedimentos}

Os participantes foram abordados numa universidade de Lisboa, onde lhes foi solicitada a colaboração. No consentimento informado a experiência foi descrita de forma breve. De início foram preenchidos os dados sociodemográficos (e.g., idade, sexo, habilitações académicas, estado civil, etnia, religião) e a escala de IE. Em seguida, foi descrito o tipo de cenário das entrevistas e explicada a tarefa, que consistia em responder a um breve questionário sobre a percepção da honestidade ou da mentira de várias pessoas. Cada participante visionou individualmente as oito entrevistas em sequências aleatórias. Foi pedido que indicasse o número do vídeo que tinha visualizado, que assinalasse se já tinha visto ou se tinha conhecimento anterior acerca dos indivíduos sob observação. Não foi fornecida qualquer outra informação ao participante durante a experiência. No fim da sessão foi dada informação (debriefing), tendo sido explicados com maior detalhe os objectivos da experiência.

\section{Resultados}

\section{Detecção da mentira e da honestidade}

Numa primeira fase, avaliou-se os resultados para os acertos em geral (honestidade e mentira, em conjunto). Verificou-se que o mínimo foi de zero acertos e o máximo de seis acertos, com uma média abaixo dos quatro acertos $(M=3,20 ; D P=1,21)$. Efectivamente, em média apenas $40 \%$ responderam correctamente a mais de três vídeos sobre a honestidade/desonestidade dos alvos. 
Com o intuito de testar se o número de acertos dependeu da honestidade ou da mentira do alvo, em função do sexo do participante e do sexo do alvo, foi efectuada uma Análise de Variância (ANOVA) com os seguintes três factores: 2 (Sexo do participante) X 2 (Sexo do alvo) x 2 (Honestidade do alvo: honesto vs desonesto). O primeiro factor (Sexo do participante) é inter-sujeito e os restantes dois (Sexo do alvo e Honestidade do alvo) são intra-sujeitos. Para facilitar a compreensão dos resultados, apresentamos os valores em termos das médias de percentagens de acertos (Ver Figura 1).

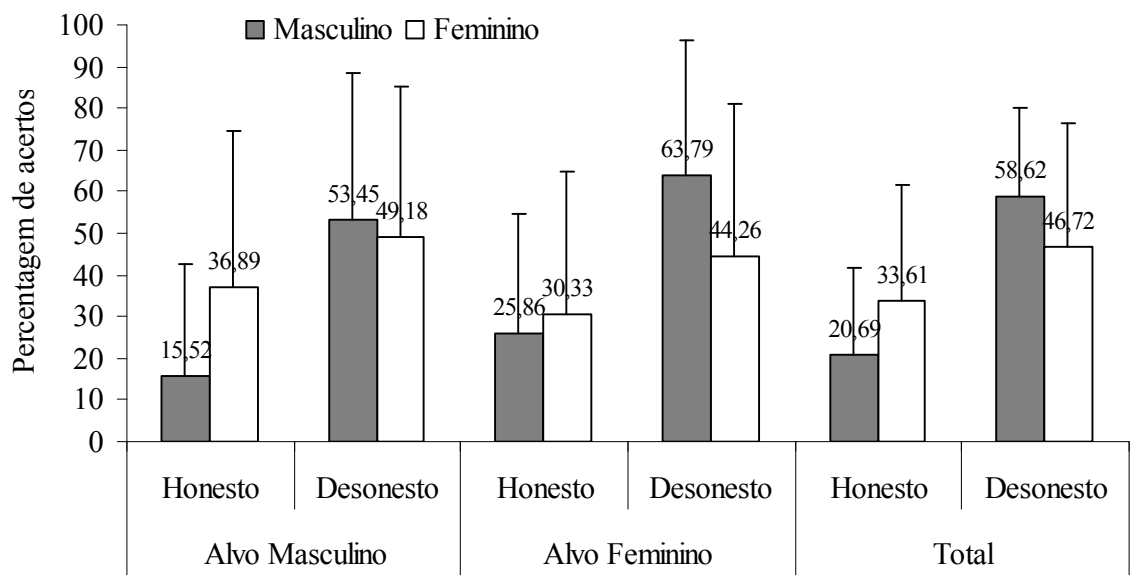

Figura 1. Média da percentagem de acertos na detecção da mentira e da honestidade em função do sexo do participante e do sexo do alvo. As barras de erros representam os desvios-padrão das médias em percentagens.

Registou-se um efeito principal da Honestidade do alvo, $F(1,88)=$ $26,47, p<0,001, \eta_{\mathrm{p}}^{2}=0,23$, e efeitos de interacção entre Honestidade do alvo X Sexo do participante, $F(1,88)=6,26, p<0,05, \eta_{\mathrm{p}}^{2}=.07$, e entre Sexo do alvo x Sexo do participante, $F(1,88)=5,12, p<0,05, \eta_{\mathrm{p}}^{2}=.06$. As interacções foram analisadas com base em análises de efeitos simples da interacção, com ajustamentos Bonferroni.

O efeito principal da condição Honestidade do alvo mostra que ocorreram mais acertos quando o alvo mentiu $(M=50,56 \% ; D P=27,79)$ do que quando foi honesto $(M=29,44 \% ; D P=26,65)$. O número de acertos na detecção da mentira mostrou-se negativamente associado à detecção da honestidade, $r(90)=-0,38, p<0,001$, sugerindo que quanto maior o número de acertos na mentira, menor o número de acertos na honestidade do alvo, e vice-versa. No entanto, tendo em conta que metade dos alvos na presente 
investigação mentiu e a outra metade testemunhou a verdade, é possível que tenham ocorrido enviesamentos nos julgamentos (i.e., tendência para julgar os alvos como honestos ou, por contraste, como mentirosos). Por esta razão, avaliou-se a diferença entre o número de respostas para julgamentos de mentira e o número de respostas de julgamentos sobre a honestidade dos alvos. Valores "zero" indicam a ausência de enviesamento. Verificou-se que a maioria dos participantes $(70 \%)$ manifestou tendência para responder que os alvos mentiram; $20 \%$ manifestou enviesamentos sobre a honestidade dos alvos; e apenas $10 \%$ não manifestaram enviesamentos.

No que se refere à interacção entre a Honestidade do alvo e o Sexo do participante, os resultados evidenciaram que, quando o alvo é honesto, o sexo feminino identifica mais vezes a honestidade $(M=33,61 \%$; $D P=$ $28,09 \%)$ do que o sexo masculino $(M=20,69 \% ; D P=21,20 \%), F(1,88)=$ $4,81, p<0,05, \eta_{\mathrm{p}}^{2}=.05$. Quando o alvo mente, o resultado tende a inverter-se, havendo uma tendência para os participantes do sexo masculino identificarem mais correctamente a mentira $(M=58,62 \% ; D P=21,42 \%)$ do que o sexo feminino $(M=46,72 ; D P=29,75 \%), F(1,88)=3,71, p=0,057, \eta_{\mathrm{p}}^{2}=$ .04. Porém, é de notar que, com excepção da identificação da mentira por parte do sexo masculino, nas restantes situações a percentagem de acertos foi inferior a 50\%. É igualmente importante ter em consideração o enviesamento nos julgamentos. Assim, apesar de ambos os sexos mostrarem um enviesamento para julgamentos de "mentira", houve diferenças de género significativas, $t(88)=2,50, p<0,05$. Os homens responderam um maior número de vezes que os alvos mentiram do que as mulheres $(M=3,03$ vs. $M=1,05)$ (note-se que os valores positivos indicam que houve uma maior tendência para julgar os alvos como mentirosos do que honestos, já que corresponde à diferença no número de respostas para julgamentos de mentira em relação a respostas de julgamentos sobre a honestidade).

Quanto ao efeito de interacção Sexo do alvo x Sexo do participante, verificou-se no sexo masculino que o número de acertos, quando o alvo é feminino, é marginalmente superior $(M=44,83 \% ; D P=20,46 \%)$ ao número de acertos quando o alvo é masculino $(M=34,48 ; D P=20,50), F(1,88)=$ $3,13, p=0,08, \eta_{\mathrm{p}}^{2}=.03$. Para os participantes do sexo feminino, o resultado, embora inverso $(M=43,03 \%, D P=24,64 \%$ para alvo masculino e $M=$ $37,30 \%, D P=20,22$ para alvo feminino), foi praticamente semelhante, não se registando diferenças significativas nas médias de acertos em função do sexo do alvo, $F(1,88)=2,02, p>0,10$.

\section{Indicadores de mentira}

A maioria dos indícios de mentira considerados neste estudo (cf. The Global Deception Team, 2006) foi assinalada em percentagem superior a 
$50 \%$. Dos nove indícios em análise, foram referidos em média cerca de cinco indícios $(M=4,82 ; D P=1,67)$. Os mais mencionados foram a "expressão facial" (95,3\%), o "nervosismo" (82,6\%), "desviar o olhar" $(73,3 \%)$, os "movimentos corporais" (62,8\%) e "hesitar" $(61,6 \%)$. O indicador considerado menos relevante foi a "incoerência" (14\%).

Houve diferenças de género no número de indícios mencionados, de modo que os homens referiram maior número de indícios do que as mulheres $(M=5,39$ vs. $M=4,55), t(68)=2,45, p<0,05$. Por outro lado, os participantes do sexo masculino (por comparação com as mulheres) reportaram com maior frequência que a "inconsistência", $\chi 2(1, n=86)=5,50, p<0,05$, a "incoerência", $\chi 2(1, n=86)=4,22, p<0,05$, e os "movimentos corporais", $\chi^{2}(1, n=86)=4,43, p<0,05$, são os indicadores que tiveram em consideração na avaliação da mentira dos alvos. Por contraste, "corar" foi referido pelas mulheres maior número de vezes quando os alvos eram percebidos como desonestos, $\chi^{2}(1, n=86)=4,17, p<0,05$.

\section{Correlações entre o número de acertos e a Inteligência Emocional}

Por último, foram efectuadas correlações de Pearson entre as dimensões da escala IE e o número de acertos, para o conjunto da amostra e em função da honestidade/mentira dos alvos de ambos os sexos. Apenas foi estatisticamente significativa a associação positiva entre a dimensão "Compreensão das emoções próprias" e o número de acertos quando o alvo era do sexo feminino, $r(90)=0,21, \mathrm{p}<0,05$, embora o valor da correlação fosse reduzido.

\section{Discussão}

O presente estudo teve como principal objectivo testar a capacidade na detecção da mentira e da honestidade em função do sexo do participante e do sexo do alvo, bem como analisar os indícios que as pessoas mais referem quando detectam a mentira no alvo. Pretendeu-se ainda verificar a associação entre essa capacidade e a IE.

Em primeiro lugar, destaca-se que a média de acertos no geral foi muito reduzida (40\%). A literatura neste âmbito tem referido valores globais de acertos inferir a 55\%, sendo $50 \%$ consideradas estimativas ao acaso (Bond \& DePaulo, 2008). Os resultados obtidos mostram assim dificuldades dos participantes em detectarem a mentira e a honestidade nos outros. O máximo de acertos não ultrapassou os seis, dos oito possíveis (correspondente a 75\%), não havendo quem conseguisse identificar a honestidade e a mentira na totalidade. $\mathrm{O}$ valor máximo de acertos é próximo do referido na literatura. Por exemplo, na meta-análise efectuada por Bond e DePaulo (2008), foi 
observada em média uma percentagem máxima de $75.70 \%$ de acertos com base em 93 amostras sob análise. São possíveis várias interpretações para estes resultados. Assim, à semelhança de outros estudos, a presente investigação não recorreu a avaliações presenciais dos comportamentos em que participante e alvo são apresentados face a face; por outro lado, os alvos não foram sujeitos a um julgamento em que a necessidade de mentir fosse eminente, como habitualmente ocorre em julgamentos efectuados em contexto prisional. Estes procedimentos podem ter contribuído para aumentar a dificuldade dos participantes em identificar indícios de honestidade e de mentira que lhes permitissem uma maior precisão nas suas respostas (cf. Ekman et al., 1999).

É igualmente importante destacar que houve uma maior percentagem de acertos quando o alvo mentiu $(50,56 \%)$ do que quando foi honesto $(29,44 \%)$. Numa primeira leitura, os resultados parecem contradizer a investigação na área, que mostra a maior facilidade das pessoas em identificar a verdade do que a mentira (e.g., Levine et al., 1999). No entanto, é possível que as instruções fornecidas - "detectar a mentira e a honestidade nos outros" - possa ter tornado saliente a presença de "mentira" nos alvos, contribuindo assim para enviesamentos nas respostas dos participantes. Verificou-se, efectivamente, que a maioria das respostas dos participantes foi no sentido de julgar os alvos como mais mentirosos do que honestos. De qualquer modo, destaca-se ainda que o número de acertos na detecção da mentira não aumentou para valores superiores ao que é referido na literatura, embora se verificasse que o número de acertos na detecção da honestidade tivesse sido muito reduzido e inferior ao esperado. A maior atenção focada na detecção da mentira pode assim explicar a maior precisão na sua detecção do que na da honestidade. É possível que, em contextos naturais, as pessoas não estejam tão alerta para a mentira. Mas como referem Hurd e Noller (1988), torna-se difícil estudar a mentira em contexto de laboratório, sem que o engano se torne muito saliente. Por outro lado, atendendo a que os participantes foram explicitamente solicitados a avaliar o comportamento de outros, também não é possível afirmar algo sobre a sua espontaneidade (cf. Ambady \& Rosenthal, 1992). Outra interpretação para estes resultados prende-se com o modo como as entrevistas aos alvos foram efectuadas. É possível que a presença da câmara de vídeo influenciasse os comportamentos dos alvos durante a entrevista, contribuindo para que se sentissem pouco à-vontade. A manifestação de desconforto ou de pouca espontaneidade do alvo pode ter contribuído para uma maior desconfiança dos participantes sobre os testemunhos dos alvos. É igualmente possível que existam diferenças individuais na capacidade destes indivíduos em mentir e reproduzir os indícios que são espontaneamente usados para a ocultar. Assim, para minimizar os efeitos da simulação no comportamento dos indivíduos e posterior influência no julgamento, parece-nos relevante que futuras investigações 
incluam um grupo de desonestos "espontâneos", ao invés da utilização de entrevistas a indivíduos a quem é pedido que "minta". Será também importante que cada pessoa-estímulo seja filmada a mentir e a dizer a verdade, para controlo de diferenças individuais. $\mathrm{O}$ recurso a um maior número de pessoas-estímulo será igualmente importante para aumentar a confiança na validade externa dos resultados obtidos.

Quanto à comparação entre géneros, observou-se um efeito de interacção entre o sexo do participante e a honestidade do alvo, indicador de que as mulheres identificam com mais precisão a honestidade, enquanto os homens são mais precisos a detectar a mentira. Este resultado é interessante e é contrário à pesquisa existente, que mostra não existirem diferenças de género neste tipo de julgamentos, em particular no que se refere à mentira. No entanto, devemos ter em consideração que os homens apresentaram um maior enviesamento para julgar os alvos como mentirosos. A investigação tem mostrado que as pessoas cépticas e desconfiadas em relação aos outros têm maior tendência para acreditar que os outros são desonestos (Levine \& McCornack, 1991). A este propósito, Hurd e colaboradores (1988) verificaram que os homens tinham tendência para suspeitar mais da honestidade do que da mentira. É possível que esta maior desconfiança nos outros por parte dos homens possa ter contribuído para o maior enviesamento nas suas respostas, o que por sua vez pode explicar a maior precisão na detecção da mentira e menor precisão quando os alvos eram honestos. Seria assim importante, em futuras investigações, determinar os processos psicológicos explicativos dos resultados obtidos.

Verificou-se ainda uma tendência marginal para maiores acertos em participantes do sexo masculino quando o alvo era feminino sugerindo, numa primeira leitura, a maior capacidade dos homens em detectar indícios nas mulheres do que em pessoas do mesmo sexo. No entanto, alguma cautela é necessária neste tipo de conclusão. Em primeiro lugar, porque a diferença é marginalmente significativa; em segundo lugar, porque a percentagem de acertos é baixa; em terceiro lugar, porque os resultados sobre a detecção da mentira e da honestidade sugerem algum cuidado na generalização deste resultado para os dois tipos de julgamento; e em quarto lugar, por ser um resultado oposto à teoria e à investigação na área, que sugere que díades do mesmo sexo poderão estar mais habilitadas a identificar com precisão indícios de comportamento não verbal e verbal. Por estas razões, este resultado parece-nos inconclusivo e merecedor de investigação adicional.

Os resultados relativos aos indícios comportamentais na detecção da mentira vão, de um modo geral, ao encontro das crenças do senso comum a este propósito e mostram-se consistentes com a investigação na área (e.g., The Global Deception Team, 2006; Vrij, 2004; Vrij \& Taylor, 2003). Efectivamente, a maioria dos participantes referiu como mais relevantes para a 
detecção da mentira os indicadores não verbais, entre os quais se destacam aqueles que a literatura tem mostrado serem inadequados na sua detecção (i.e., "nervosismo", "desviar o olhar" e os acentuados "movimentos corporais"). Por contraste, os indícios verbais, como a "incoerência", as "pausas" e a "inconsistência", foram assinalados como menos relevantes. De qualquer modo, foram os homens que referiram basear-se em maior número de indícios do que as mulheres, embora seja de assinalar a existência de diferenças de género no tipo de indícios. As mulheres, por comparação com os homens, levam menos em consideração indicadores verbais, como a "inconsistência" ou a "incoerência", e como mais relevante "corar". É possível que estes resultados possam estar relacionados com a maior atenção que geralmente as mulheres dedicam aos indícios emocionais (e.g., Freudenthaler, Neubauer, \& Haller, 2008).

Quanto à relevância da IE para a detecção da mentira e da honestidade, os resultados foram pouco reveladores. A investigação sobre a existência de diferenças individuais na detecção da mentira e da honestidade é reduzida embora, no geral, não tenha identificado com consistência traços que se associem a maior precisão neste tipo de julgamentos (ver meta-análises de Aamodt \& Custer, 2006; Bond \& DePaulo, 2006, 2008). No presente estudo, verificou-se apenas que um maior relato de compreensão das próprias emoções se associa a um maior número de acertos em alvos do sexo feminino. No entanto, o valor da correlação foi reduzido. $O$ facto de o valor ser baixo e por ter sido a única dimensão da IE associada ao número de acertos, leva-nos a minimizar a relevância deste resultado e a considerar a possibilidade de ser espúrio. De facto, entre as diferentes dimensões da IE, seria de esperar que fossem as dimensões interpessoais (e.g., compreensão das emoções nos outros e empatia) as principais preditoras da detecção da mentira e da honestidade. De qualquer modo, seria interessante conduzir investigação adicional sobre a relevância da compreensão das próprias emoções no tipo de julgamentos em estudo, no sentido de perceber a consistência deste resultado. Estudos anteriores evidenciaram que a auto-monitorização parece ser relevante para a detecção de mentira (cf. Aamodt \& Custer, 2006). Algumas das características centrais em indivíduos com elevada auto-monitorização são a capacidade de prestar atenção, regular, controlar e alterar o seu comportamento, de modo a ajustar-se às circunstâncias sociais. Esta capacidade de adaptação e de mudança poderá implicar maior consciência de si próprio, em termos de sentimentos e pensamentos, estando associado à IE (Schutte et al., 2001). É possível, por isso, que uma maior compreensão das próprias emoções se mostre associada a maior capacidade para fazer julgamentos mais precisos sobre a mentira e a honestidade dos outros. De qualquer forma, deve-se também ter em conta que a IE foi medida através um instrumento de auto-avaliação e portanto sujeita a limitações próprias (e.g., desejabilidade 
social). Os resultados obtidos evidenciam a necessidade de ser realizada investigação adicional sobre este conceito, nomeadamente através de outro tipo de medida. Na actualidade, a investigação sobre variáveis individuais é reduzida e baseada fundamentalmente em escalas de auto-relato. Seria interessante em estudos futuros analisar variáveis desta natureza com recurso a medidas indirectas.

Apesar das limitações referidas, gostaríamos de concluir reafirmando a reduzida capacidade que as pessoas têm para detectar a mentira e a honestidade nos outros. Salientamos também que a identificação de factores que afectam a sua precisão continua por esclarecer. No presente trabalho investigámos o papel do género, considerando o sexo do alvo e a honestidade/mentira do alvo. Avaliou-se ainda a relação entre a precisão neste tipo de julgamentos e a IE. Embora tenham sido detectadas diferenças de género, a maioria das dimensões da IE não se mostrou associada a maior precisão nos julgamentos efectuados.

A importância da identificação de factores individuais e contextuais que ajudem a detectar a mentira permanece central para a Psicologia, nomeadamente em áreas tão diversas como a Psicologia Forense, Psicologia Organizacional, Psicologia Social e Psicologia Clínica. Trata-se portanto de um fenómeno social de extrema relevância, pelo que será necessário dar continuidade a estudos nesta área de investigação.

\section{Referências}

Aamodt, M., \& Custer, H. (2006). Who can best catch a liar?. Forensic Examiner, 15, 6-11.

Ambady, N., \& Rosenthal, R. (1992). Thin slices of expressive behavior as predictors of interpersonal consequences: A meta-analysis. Psychological Bulletin, 111, 256-274.

Bond, C. F., \& DePaulo, B. M. (2006). Accuracy of deception judgments. Personality and Social Psychology Review, 10, 214-234.

Bond, C. F., \& DePaulo, B. M. (2008). Individual differences in judging deception: Accuracy and bias. Psychological Bulletin, 134, 477-492.

Bueno, J., \& Primi, R. (2003). Inteligência emocional: Um estudo de validade sobre a capacidade de perceber emoções. Psicologia: Reflexão e Crítica, 16, 279-291 .

Crossman, A., \& Lewis, M. (2006). Adults' ability to detect children's lying. Behavioral Sciences and the Law, 24, 703-715.

DePaulo, B. M., Epstein, J. A., \& Wyer, M. M. (1993). Sex differences in lying: How men and women deal with the dilemma of deceit. In M. Lewis \& C. Saarni (Eds.), Lying and deception in everyday life (pp. 126-147). New York: Guilford. 
DePaulo, B. M., Kirkendol, S. E., Kashy, D. A., Wyer, M. M., \& Epstein, J. A. (1996). Lying in everyday life. Journal of Personality and Social Psychology, 70, 979-995.

Edelstein, R. S., Goodman, G. S., Ekman, P., \& Luten, T. L. (2006). Detecting lies in children and adults. Law and Human Behaviour, 30, 1-10.

Ekman, P., Franck, M. G., \& O’Sullivan, M. (1999). A few can catch a liar. Psychological Science, 10, 263-266.

Ekman, P., \& O' Sullivan, M. (1991). Who can catch a liar?. American Psychologist, 46, 913-920.

Ennis, E., Vrij, A., \& Chance, C. (2008). Individual differences and lying in everyday life. Journal of Social and Personal Relationships, 25, 105-118.

Freudenthaler, H., Neubauer, A., \& Haller, U. (2008). Emotional intelligence: Instruction effects and sex differences in emotional management abilities. Journal of Individual Differences, 29, 105-115.

Gervais, J., Tremblay, R., \& Héroux, D. (1998). Boys' lying and social adjustment in pre-adolescence: Teachers', peers' and self-reports. Criminal Behaviour and Mental Health, 8, 127-138.

Hall, J. A. (1984). Nonverbal sex differences: Communication accuracy and expressive style. Baltimore: The John Hopkins University Press.

Hurd, K., \& Noller, P. (1988). Decoding deception: A look at the process. Journal of Nonverbal Behavior, 12, 217-233.

Levine, T. R., Park, H. S., \& McCornack, S. A. (1999). Accuracy in detecting truths and lies: Documenting the "veracity effect." Communication Monographs, 66, 125-144.

Maltz, D. N., \& Borker, R. A. (1982). A cultural approach to male-female miscommunication. In J. J. Gumperz (Ed.), Language and social identity (pp. 196-216). New York: Cambridge University Press.

Mann, S., Vrij, A., \& Bull, R. (2004). Detecting true lies: Police officers' ability to detect deceit. Journal of Applied Psychology, 89, 137-149.

Masip, J. (2005). Is the liar caught sooner than the cripple? Popular wisdom versus scientific knowledge on the non-verbal detection of deception. Papeles del Psicólogo, 26, 78-91.

Rego, A., \& Fernandes, C. (2005). Inteligência emocional: Contributos adicionais para a validação de um instrumento de medida. Psicologia, XIX, 139-167.

Schutte, N. S., Malouff, J. M., Bobik, C., Coston, T. D., Greeson, C., Jedlicka, C., Rhodes, E., \& Wendorf, G. (2001). Emotional intelligence and interpersonal relations. Journal of Social Psychology, 141, 523-536.

Stapel, D. A., Koomen, W., \& van der Pligt, J. (1996). The referents of trait inferences: The impact of trait concepts versus actor-trait links on subsequent judgments. Journal of Personality and Social Psychology, 70, 437-450.

The Global Deception Team (2006). A world of lies. Journal of Cross-Cultural Psychology, 37, 60-74.

Vrij, A. (2004). Why professionals fail to catch liars and how they can improve. Legal and Criminological Psychology, 9, 159-181. 
Vrij, A., \& Taylor, R. (2003). Police officers' and students' beliefs about telling and detecting little and serious lies. International Journal of Police Science and Management, 5, 1-9.

Zeidner, M., Roberts, R., \& Matthews, G. (2008). The science of emotional intelligence: Current consensus and controversies. European Psychologist, 13, 64-78. 